\title{
Narrativas sobre riscos naturais e resiliência na construção da agenda urbana global neoliberal
}

\author{
Narratives about natural risks and resilience \\ in the construction of the global neoliberal urban agenda
}

Alexandre Sabino do Nascimento [I] Caline Mendes de Araújo [II]

\section{Resumo}

Este artigo objetiva realizar uma abordagem acerca dos riscos (socioambientais) e da ideia de resiliência, discutindo as suas principais acepções e usos contemporâneos no debate sobre a urbanização mundial, e como esses termos estruturantes encabeçam as narrativas da agenda urbana global encampada por organismos multilaterais. 0 estudo possui caráter exploratório/analítico, partindo de levantamentos, leituras e análises bibliográficas/documentais. As narrativas sobre os riscos socioambientais, associadas à ideia de resiliência, são utilizadas no planejamento/gestão urbana atual das cidades em diferentes contextos. Verificou-se que o mercado tem transformado essas dinâmicas e problemáticas socioambientais em grandes negócios "sustentáveis", transferindo, difundindo e mobilizando tais discursos e suas "soluções" para diferentes problemas urbanos, visando implementar o ideário da agenda global de urbanização neoliberal e "sustentável".

Palavras-chave: risco; resiliência; urbanização neoliberal; grandes negócios; agenda urbana.

\begin{abstract}
This article aims to approach (socio-environmental) risks and the idea of resilience, discussing their main contemporary meanings and usages in the debate on world urbanization and how these structuring terms head the narratives of the global urban agenda taken up by multilateral organizations. The study has an exploratory/analytical character, based on surveys, readings and bibliographic/ documentary analyses. Narratives about socioenvironmental risks, associated with the idea of resilience, are used in the current urban planning and management of cities in different contexts. We found that the market has transformed these dynamics and socio-environmental problems into big "sustainable" businesses, transferring, disseminating and mobilizing such discourses and their "solutions" for different urban problems, aiming to implement the ideas of the global neoliberal and "sustainable" urbanization agenda.
\end{abstract}

Keywords: risk; resilience; neoliberal urbanization; big businesses; urban agenda. 


\section{Introdução}

0 presente estudo apresenta uma reflexão sobre as terminologias/noções de risco (socioambiental), resiliência e temáticas afins, considerando-as dentro de processos mais amplos ligados ao fenômeno da "urbanização planetária" (Brenner, 2014 e 2018) ou "Era Urbana" (ONU-Habitat, 2016) e vinculando-as a uma abordagem presente na chamada Teoria Urbana Crítica (Brenner, 2018) e suas possibilidades para a análise da relação sociedade-natureza presente no processo de produção do espaço urbano contemporâneo.

Nesse contexto, destaca-se a intensificada importância do capital financeiro na produção do espaço; tal capital possui características como volatilidade, instabilidade, bem como incerteza. 0 capital financeiro vem impondo seus interesses sobre agentes, ações, processos e espaços, em suas mais diversas escalas, tirando proveito das fragilidades dos territórios por meio do emprego de narrativas e dispositivos que promovem a desresponsabilização do Estado perante as populações vulneráveis social e ambientalmente das cidades do sul global, além de vender suas ditas "boas práticas" como soluções para toda sorte de problemas urbanos.

0 artigo, também, visa contribuir com a análise sobre as principais motivações da origem e da manutenção dos riscos (socioambientais), buscando ir além de uma explicação puramente "naturalizante" ou antrópica, lembrando que, dentre as causas fundantes de tais problemáticas, frequentemente, estão os elementos sociais, como a pobreza e a desigualdade, assim como outras contradições do sistema capitalista. Tais problemáticas se encontram, mais do que nunca, localizadas no espaço urbano, associadas à urbanização planetária, neoliberal e desigual, vivenciadas nas cidades pelo mundo afora, com destaque para as cidades dos países periféricos do capitalismo tardio e com suas crescentes injustiças socioambientais (Brenner, 2018; Brenner, Peck e Theodore, 2015; Davis, 2004; Araújo e Nascimento, 2019).

No processo de produção do paradigma da urbanização planetária (Brenner, 2014), que a própria $\mathrm{ONU}$ vem difundindo como macrotendência mundial (ONU-Habitat, 2016), a taxa de urbanização mundial alcançou a marca de $54,5 \%$, e os desafios colocados para o desenvolvimento urbano tornaram-se ainda maiores. Porém, esse crescimento não é homogêneo. As áreas que mais se urbanizam são as frações mais pobres dos países menos desenvolvidos do planeta, acompanhadas do crescimento da pobreza e da desigualdade (Davis, 2004), ${ }^{1}$ associadas a problemas socioambientais.

As recentes crises do sistema capitalista fizeram com que países (semi)periféricos, como o Brasil, com suas economias dependentes (Paulani, 2008), inserissem-se no processo de internacionalização e financeirização do capital de forma subordinada (Büedenbender e Aalbers, 2019). Tal fato tem produzido espaços com alto padrão de desigualdade e mais suscetíveis à conformação de riscos e de vulnerabilidades socioambientais. Para remediar essas problemáticas, os países supramencionados têm sido levados a utilizar uma série de dispositivos (Agamben, 2005) como soluções ilusórias - as chamadas "boas práticas", vinculadas a narrativas/conceitos como os de sustentabilidade urbana, cidades inteligentes, inclusivas e resilientes, entre outros. 
Vale ressaltar que as chamadas "boas práticas" são defendidas como única via para redução da pobreza urbana mundial e para o pretenso desenvolvimento sustentável das cidades, e são inseridas via a formação de agendas e arenas globais de ação e difusão de políticas urbanas (Sabatier e Weible, 2007; Stone e Ladi, 2015). Esses conceitos e narrativas possuem um potencial integrador e consensual que são pré-requisitos básicos para a construção de uma nova agenda urbana global. Tal processo é capitaneado por agentes transnacionais, que agem de modo multiescalar (Brenner, 2020). Esses agentes são responsáveis pela transferência, difusão e mobilidade de políticas públicas urbanas neoliberais na América Latina e no mundo (Jajamovich, 2013; Peck e Theodore, 2010; Stone e Ladi, 2015).

Diante disso, o presente artigo, mediante reflexões sobre a produção do espaço urbano dentro do paradigma do urbanismo neoliberal (Brenner, Peck e Theodore, 2015; Brenner, 2018), tem como objetivo principal realizar uma reflexão crítica sobre os conceitos de risco e resiliência e a ligação deles com a construção de narrativas/discursos e agendas urbanas que viajam o mundo e se materializam, sem quase nenhuma mediação territorial e histórica, na forma de políticas públicas ligadas às problemáticas socioambientais nos mais diferentes contextos espaço-temporais.

Acredita-se que agendas globais, como a dos Objetivos do Desenvolvimento Sustentável - ODS, que representam o eixo central da Agenda 2030 da ONU (ONU, 2020), ${ }^{2}$ ou como a Nova Agenda Urbana (ONU-Habitat, 2016), vêm se utilizando das polêmicas narrativas das mudanças climáticas e da sociedade do risco global (Beck, 1998), com a finalidade de construir uma agenda de urbanização dita sustentável ou de produzir cidades sustentáveis e/ou inteligentes via crescentes investimentos públicos e privados ou conformação de "parcerias público-privadas globais" (Stone e Ladi, 2015). Tudo isso tem levado a um crescente endividamento de cidades e países, que funciona como um aparato ou dispositivo de captura de seus governos (Lazzarato, 2015). Nessa agenda, conceitos-chave como risco, sustentabilidade (urbana) e resiliência são assimilados de forma acrítica.

A presente pesquisa possui um caráter exploratório/analítico e é do tipo qualitativa, bibliográfica e documental. Nela foram analisados documentos das instituições multilaterais promotoras da difusão do discurso da governança urbana neoliberal e da sustentabilidade urbana, assim como a bibliografia relativa aos conceitos analisados e de temáticas correlatas. Portanto, trata-se de uma pesquisa que visa à abertura de um debate necessário sobre a produção de agendas globais ligadas ao atual contexto da urbanização planetária e da chamada sociedade de risco.

$O$ texto divide-se em duas partes, além da Introdução e das Considerações finais. $\mathrm{Na}$ primeira parte do artigo, apresenta-se a discussão sobre a origem, o uso e a difusão das principais abordagens e conceitos relacionados à temática do texto, com ênfase na reflexão sobre a relação sociedade-natureza e no conceito de risco. Na segunda parte do texto, discorre-se sobre o conceito de resiliência e seu emprego dentro da conformação de uma agenda global ligada à urbanização neoliberal, planetária e desigual, baseada no paradigma da "sociedade de risco global", vinculado à questão das mudanças climáticas. Destaca-se, ainda, a formação de grandes negócios vinculados aos riscos e desastres, por parte do capital financeiro. 


\section{A relação sociedade-natureza e os riscos socioambientais: um debate crítico sobre as principais concepções}

Certas discussões sobre a produção do espaço, no âmbito da Geografia, têm tentado retomar o debate sobre intrínseca relação sociedade-natureza que foi e ainda é muito cara à essa ciência (Suertegaray, 2017), mas também a outras áreas do conhecimento. ${ }^{3}$ De acordo com Mendonça (2009, p. 124), "a geografia é uma ciência voltada ao estudo da produção do espaço a partir da interação Sociedade-Natureza".

Chama-se a atenção para essa ciência, pois ele, devido ao seu potencial explicativo e às suas prerrogativas teórico-metodológicas, pode auxiliar a compreender a complexidade/ totalidade presentes em problemáticas socioambientais e no discurso do desenvolvimento sustentável e de seus conceitos correlatos, a exemplo de sustentabilidade, resiliência, serviços ambientais/ecossistêmicos, cidades sustentáveis, mercado de títulos verdes entre outros. Algumas dessas narrativas podem ser encontradas na Agenda 2030 da ONU para o Desenvolvimento Sustentável e seus 17 Objetivos de Desenvolvimento Sustentável - ODS ${ }^{4}$ e no Acordo de Paris ${ }^{5}$ (Nascimento, 2020).

No que se refere às análises sobre a relação natureza-sociedade, os aspectos e variáveis naturais têm, por parte de alguns estudos, sido supervalorizados, negligenciados ou ainda dissociados dos elementos sociais, como será discutido adiante. Isto é bastante preocupante, tendo em vista a imbricação real entre essas dimensões da realidade. Para Mendonça (2009, p. 124): “A geografia, no seu particular, apresenta possibilidades interessantes para o tratamento desta problemática [socioambiental], mesmo se a perspectiva das ciências naturais - geografia física - e das ciências sociais - geografia humana - encontre aí vários problemas".

No tocante à complexidade da abordagem sobre a relação sociedade-natureza, a Geografia possui um arcabouço teórico-metodológico possível de dar conta das especificidades dessa relação inerentes à cidade. Segundo Moraes (2005, p. 83), “[...] não seria possível formular uma única proposta de análise ambiental para todas as ciências que estudam a sociedade, pois coexistem nesse conjunto situações diferenciadas". Há alguns pressupostos teóricos-metodológicos sobre essa relação, dentre os quais pode-se destacar: a visão holística, a visão a partir da teoria da complexidade, a visão dicotômica, a visão "relacional", entre outras. ${ }^{6}$

Nessa perspectiva, Schmidt (apud Smith, 1988) entende que há, de forma geral, duas maneiras de tratar a natureza: 1) como exterior; 2) como universal (ibid.; Moraes, 2005). Na primeira abordagem, a natureza é tratada como "exterior", pois é vista de forma isolada, como se fosse separada da sociedade; já, na segunda maneira de tratar a natureza, a natureza é apreendida como universal, ou seja, ela está, segundo esse ponto de vista, relacionada à sociedade, sendo ambas interdependentes, inseparáveis.

Pode-se afirmar que se trata, por um lado, de uma visão dicotômica (de separação da sociedade e da natureza) e, por outro lado, de uma perspectiva relacional (esta última denominação parte da contribuição e atualização feita por Harvey (2016) sobre as concepções de espaço absoluto, relativo e 
relacional), ${ }^{7}$ visto que a sociedade e a natureza estão interligadas, relacionando-se constantemente, e que são duas faces de uma mesma realidade.

Verifica-se que certas ciências, bem como alguns posicionamentos da própria Geografia, abordam a natureza mais do ponto de vista da exterioridade; outras, por sua vez, tentam tratá-la a partir da concepção universal, na qual natureza e sociedade são complementares. Pode-se encontrar, em algumas ideias ligadas ao paradigma da urbanização neoliberal, a perspectiva dicotômica, de uma natureza exterior ao homem, vista de forma isolada, de modo separado da sociedade, dissociada das determinações e contradições sociais da sociedade capitalista.

Diante do exposto e a partir da contribuição de Schmidt apud Smith (1988), serão discutidas, adiante, as abordagens que se referem à primeira apreensão (natureza exterior ou visão dicotômica), quais sejam: perspectivas natural e antrópica (Tominaga et al., 2012), assim como as apreensões que se relacionam ao outro enfoque da natureza (natureza universal ou visão relacional), a saber: perspectiva mista (ibid.), da qual a presente pesquisa tentou aproximar-se (Araújo, 2019).

Ressalta-se que a abordagem mista leva em consideração as relações entre a sociedade e a natureza, não as considerando como dimensões separadas. Essa maneira de apreensão dessas duas dimensões da realidade está contemplada na abordagem da natureza enquanto "universal", conforme se discutiu anteriormente (Smith, 1988; Moraes, 2005). Por esse motivo, trata-se, aqui, a visão mista como atrelada à perspectiva Universal da Natureza. Ademais, nenhuma abordagem é homogênea, mas são predominantes em certos contextos.
"Privilegiou-se", aqui, o debate sobre riscos, ${ }^{8}$ pois o seu uso tem se tornado cada vez mais corriqueiro, sem se desconsiderar a importância dos demais debates correlacionados, a exemplo da resiliência, que será abordada adiante. É importante lembrar que há uma ausência de consenso na literatura, com algumas exceções, no que diz respeito ao significado das terminologias analisadas, bem como no que se refere aos tipos de abordagens realizadas.

Sánchez $(2012$, p. 3) assegura que [...] no existe un concepto de riesgo que satisfaga las exigencias de todas las ciencias. Cada una de las disciplinas que se adentran en el tema utiliza el contexto teórico propio, pues les basta como guia. Para Veyret (2007, p. 16), Muitas abordagens dos riscos são possíveis e permitem concebê-los como um sistema que articula práticas de gestão, atores e espaços segundo lógicas diversas. Dentre essas lógicas, estão as ligadas aos interesses dos agentes globais hegemônicos analisados neste texto.

Existem muitos tipos de riscos (industriais, tecnológicos, sociais, econômicos) (ibid.), que envolvem variadas escalas espaciais e temporais. ${ }^{9}$ Os riscos de morte dos aventureiros, o risco da pobreza, os riscos de doenças ou pandemias, entre outros (Beck, 1998) são alguns dos exemplos. Além disso, o termo também é muito utilizado no mundo dos negócios, a exemplo das expressões "investimentos de risco" e "risco empresarial" (Almeida, 2011; Porto-Gonçalves, 2012).

O uso dessa nomenclatura não é atual (Beck, 1998), porém, a sua utilização relacionada às problemáticas que envolvem conjuntamente sociedade e natureza - ou a intensificação de problemáticas sociais preexistentes, a partir dos fenômenos da natureza - é uma 
abordagem mais recente, visto que o interesse pelas temáticas relacionadas às questões ecológicas se expande em meados de século XX (Veyret, 2007). Cantos expõe as fases de abordagens dos riscos e de algumas terminologias correlatas:

1) Se ha pasado de la catástrofe al riesgo (años 80)

2) Se ha pasado, del peligro a la vulnerabilidad (años 90)

3) Han aparecido nuevos conceptos de análisis: resistencia y resiliencia (a partir de 1998)

4) Han surgido nuevos conceptos de la "geografía de los riesgos": territorios de riesgo, región-riesgo, paisajes de riesgo

5) Por último, el riesgo natural esencialmente los vinculados al clima - integrado plenamente en el cambio climático (IPCC, 2007). (Cantos, 2008, s.p.)

Sobre a última fase há, atualmente, uma construção sociopolítica e institucional multiescalar da noção de crise climática e sua correlata legitimação via o paradigma das mudanças climáticas de causa antrópica, e não da relação sociometabólica e contraditória entre homem, tecnologia e natureza no capitalismo (Mészáros, 2011).

Essa construção compreende ações de instituições, configuração de redes de transferência e difusão de políticas públicas, produção de discursos e práticas e a ação de toda sorte de agentes, nas mais variadas escalas, envolvidos na transferência, difusão, mobilização e implementação de políticas (Peck e Theodore, 2010; Stone e Ladi, 2015) que, em nome do combate às mudanças climáticas, promovem uma ampliação dos mecanismos de mercado ligados ao chamado desenvolvimento sustentável (Furtado, 2015; Nascimento, 2020).
Observa-se, a partir de Cantos (2008), que houve muitas mudanças e reformulações nas ideias apresentadas, o que não implica dizer que haja, hoje, um consenso a respeito das terminologias que permanecem. Na concepção de Beck (1998):

La pretensión de racionalidad de las ciencias de averiguar objetivamente el contenido del riesgo se debilita a sí misma permanentemente: por una parte, reposa en un castillo de naipes de suposiciones especulativas y se mueve exclusivamente en el marco de unas afirmaciones de probabilidade cuyas prognosis de seguridad stricto sensu ni siquiera pueden ser refutadas por accidentes reales. (p. 35)

Busca-se compreender algumas dessas "especulações", uma vez que muitas dizem respeito a aproximações iniciais ou incipientes para se tratar de um tema tão polêmico e polissêmico. Há, conforme visto, uma variedade de perspectivas e abordagens sobre os riscos e terminologias/temáticas afins, algumas das quais são discutidas aqui, quais sejam: as perspectivas dicotômicas (naturalista e antrópica) - ligadas à legitimação da mudança climática de causa pretensamente antropogênica - e a abordagem relacional (mista/socioambiental), conforme exposto anteriormente. Para Romero, Fuentes e Smith (2010, s.p.):

Los actuales enfoques para tratar las cuestiones ambientales y de riesgos aparecen sesgadas a favor de las disciplinas naturales pero incapacitados de abarcar los problemas sociales y políticos, por lo que terminan en informes académicos o técnicos que no son tenidos en cuenta en la toma de decisiones, en la medida que se 
oponen o restringen los beneficios que esperan obtener autoridades públicas y empresarios privados.

É inconcebível que, sendo a sociedade (dividida em classes sociais) geradora de vulnerabilidades e uma das maiores responsáveis pelas causas mais fortes dos riscos e dos desastres - além de ser a mais afetada com toda essa dinâmica (sobretudo a parcela constituída pelos mais pobres) -, a discussão sobre o social ainda seja tão ausente em grande parte dos estudos sobre riscos, vulnerabilidades, desastres, etc. Na concepção de Thomas (1993, p. 111):

[...] los desastres son más bien fenómenos de carácter y definición eminentemente social, no solamente en términos del impacto que los caracteriza, sino también en términos de sus orígenes, así como de las reacciones y respuestas que suscitan en la sociedad política y civil.

Não se nega a presença dos fenômenos naturais nesses processos, mas reafirma-se o grande peso do social não só no pós-desastre, mas também antes, em períodos em que os problemas têm origem, ${ }^{10}$ momentos nos quais as desigualdades sociais se conformam/consolidam. ${ }^{11}$ Tais desigualdades estão associadas a aspectos históricos, sociais e econômicos, como resultado das "clivagens de classe" e outras "hierarquias sociais" (Souza, 2019). A esse respeito, Souza (ibid.) ressalta a importância de uma reflexão sobre

[...] a desigualdade na exposição aos riscos derivados dos métodos hegemônicos de organização do espaço (conforme ilustrado pela forte correlação entre segregação residencial e riscos de desastres decorrentes de desmoronamentos e deslizamentos) e na capacidade de acesso a recursos ambientais e fruição de amenidadades naturais, em função da clivagem de classe e outras hierarquias sociais. (p. 130)

Essas clivagens e hierarquias mostram que a sociedade não é um bloco homogêneo, por isso a conformação/manutenção dos riscos socioambientais, estes relacionados, também, à presença de diferentes "classes de risco" (Beck, 1998). ${ }^{12}$

Continuando a análise sobre os desastres, Thomas (1993) aponta suas diferentes espacialidades/temporalidades:

Sus orígenes trascienden el período inmediato de su concreción, remontándose al processo histórico de desarrollo o subdesarrollo de zonas, regiones o países; y, su proyección temporal también rebasa los momentos del impacto inmediato y de restauración de las condiciones básicas de existencia humana. (p. 111)

É necessário pensar acerca dessas problemáticas e das suas origens a partir do aspecto social em suas relações com a natureza, tendo em vista a importância da sociedade na conformação desses processos. Para Beck (1998, p. 30), as discussões sobre [...] la destrucción de la naturaleza y del médio ambiente en general, sigue teniendo lugar exclusiva o dominantemente mediante categorías o fórmulas propias de las ciencias naturales. Tal crítica contribui para a reflexão sobre a necessidade de uma "desnaturalização" das análises. A ideia não é omitir os fatores naturais, mas buscar ampliar a ênfase nas suas relações com a sociedade. Assim, adjetivar desastres e riscos como sendo puramente "naturais" endossa a naturalização de processos sociais, econômicos e políticos mais complexos. 
Outra perspectiva dicotômica, a antrópica, tem abordado a temática dos riscos voltando-se à análise do homem individualmente (e, raramente, da sociedade, sem levar em conta os aspectos naturais) como causador central das problemáticas nos contextos de risco. Essa abordagem, assim como a "naturalizante", limita também o entendimento acerca das origens e da manutenção desses engodos. Entretanto, essa abordagem tem ganhado força com a ofensiva neoliberal dos últimos quarenta anos. Cantos (2008, s.p.) traz uma ilustração sobre o que se vem debatendo, quando coloca o ser humano no centro do debate sobre riscos:

El riesgo ha pasado de ser la mera posibilidad de ocurrencia de un episodio extraordinario al análisis de la plasmación territorial de actuaciones llevadas a cabo por el ser humano en un espacio geográfico y que no han tenido en cuenta la dinámica propia de la naturaleza en dicho lugar. (Cantos, 2008 , s.p.)

A crítica que se faz ao exposto é que, ao analisar o contexto das abordagens sobre os riscos, o autor fala de ações realizadas pelo ser humano nos espaços, desconsiderando que as ações são da sociedade como um todo e não de indivíduos isolados, e que essa sociedade é carregada de contradições. ${ }^{13}$ Ademais, de maneira geral, a ocupação de tais espaços não ocorre porque as pessoas não pensaram na natureza, mas porque não tinham outras opções, tendo em vista o crescente encarecimento do solo e da moradia nas cidades. Acontece o contrário com os grandes agentes produtores do espaço, como os agentes imobiliários, financeiros e o Estado. Estes, sim, agem à revelia da natureza!
Não se pode continuar minimizando o cunho social das vulnerabilidades, omitindo a sociedade que inclui o Estado e os agentes do mercado imobiliário, por exemplo. Para Souza (2015, p. 26):

\begin{abstract}
Para elucidar o que se passa nos marcos das situações que envolvem algum tipo de injustiça social, é necessário ir muito além da alusão vaga a um "fator antrópico". Somente descrevendo adequadamente e compreendendo as diversas fraturas e contradições sociais e os conflitos que daí derivam (entre classes, entre frações de classe e entre grupos definidos em função de outras clivagens, tal como etnia) é que poderemos perceber e expor o quadro na sua real complexidade: o problema das assimetrias (distribuição assimétrica de ganhos, riscos e prejuízos, assim como da própria capacidade de se proteger de malefícios), da heterogeneidade de agentes e das responsabilidades e influências variáveis (mediatas e imediatas, indiretas e diretas).
\end{abstract}

Recorre-se a essa contribuição de Souza porque os contextos analisados, os "espaços em risco", muito frequentemente, dizem respeito a realidades com forte injustiça social e ambiental (Acserald, Campello e Bezerra, 2009; Araújo, 2019; Araújo e Nascimento, 2019). Os aspectos sociais trazidos pelo autor são os menos discutidos em vários âmbitos nos quais se trata ou se deveria tratar sobre riscos (escolas, prefeituras, defesa civil, universidades, mídia). Assim, considera-se bastante superficial manter as análises somente no "nível antrópico". Urge a necessidade de se pensar as dinâmicas mais gerais!

Para além das duas abordagens elencadas sobre os riscos e temas correlatos, há também a perspectiva relacional (mista/ 
socioambiental), ${ }^{14}$ a qual se acredita ser a mais pertinente. Essa visão apreende as dinâmicas naturais e sociais de forma imbricada (tendo cada uma delas a sua relevância e particularidades) e a sociedade enquanto totalidade.

Nesse sentido, Filgueira (2013, p. 54) afirma: "[...] o desastre é um problema da relação entre o natural e a organização e estrutura da sociedade". A esse respeito, Mendonça (2010, p. 154) expõe que:

A abordagem dos riscos socioambientais urbanos pode ser concebida como um novo paradigma, na medida em que muda o foco da compreensão da lógica de produção e reprodução socioespacial; ou seja, ela atesta a inserção de uma nova base de análise na relação sociedade - natureza, pois salta de uma base de certeza e estabilidade para uma outra de incerteza e de instabilidade quanto à repercussão dos processos naturais e sociais do espaço geográfico.

Entende-se, com Wilches-Chaux (1993, p. 19), que los desastres son fenómenos eminentemente humanos y sociales $y$, em consecuencia, debemos despojarlos del calificativo de "naturales" que genera la sensación de que el mundo "es así" y no podemos hacer nada para evitarlo. ${ }^{15}$ De acordo com Tominaga et al. (2012, p. 15):

Além da intensidade dos fenômenos naturais, o acelerado processo de urbanização verificado nas últimas décadas, em várias partes do mundo, inclusive no Brasil, levou ao crescimento das cidades, muitas vezes em áreas impróprias à ocupação, aumentando a situação de perigo e de riscos a desastres naturais.

Assim, pode-se pensar a respeito da responsabilidade da sociedade erigida pelo capital em processos acentuadores das possibilidades de desastres e injustiças socioambientais, a exemplo da urbanização desigual e da ocupação em áreas impróprias à moradia, tendo em vista a ausência "planejada" do Estado enquanto mediador dos problemas habitacionais, além das desiguais formas de produção e apropriação do espaço.

Mendonça (2010) enfatiza a importância desse paradigma que valoriza a relação sociedade-natureza nas análises referentes aos riscos e expõe que: "não se trata de abordá-los de um ponto de vista apenas natural ou social, ainda que se possa fazê-lo, mas de buscar evidenciar sua expressão geográfica tendo por base a imbricação direta dos diferentes elementos componentes do espaço geográfico" (p. 156). Pode-se, então, também designá-los de riscos socioambientais (ibid.; Araújo, 2019; Araújo \& Nascimento, 2019).

Ainda sobre a noção de risco, Mendonça (2010) assinala que ela forja "[...] a mudança da concepção predominante de estabilidade do espaço ou da natureza, uma vez que se fundamenta na ideia de incerteza quanto às paisagens futuras, especialmente ao admitir os processos de mudanças globais e globalização em curso" (p. 156). Trata-se, pois, das incertezas do porvir, ${ }^{16}$ diante das dinâmicas em diversas escalas. ${ }^{17}$

Nesse cenário, Romero, Fuentes e Smith (2010, s.p.) afirmam que Más allá de intentar explicar el aumento de los desastres naturales como consecuencia de los cambios climáticos o de los fenómenos de El Niño, es evidente que se trata de asuntos de injusticia ambiental y territorial [...]. Essa colocação é pertinente, pois tira o foco da discussão que se coloca nos fenômenos naturais e antrópicos ${ }^{18}$ isoladamente e traz o debate para o nível das injustiças sociais e ambientais. 


\section{0 "mundo em risco"? a ascensão de narrativas neoliberais sobre os riscos e resiliência nas cidades e a construção de um grande negócio}

As discussões contemporâneas sobre desastres, no Brasil e no mundo, têm trazido, de forma recorrente, outras terminologias associadas aos riscos, a exemplo do termo resiliência. Essa terminologia - e suas derivações - já vem sendo muito utilizada também pelos órgãos de Proteção e Defesa Civil de grande parte do mundo. Conforme Pacheco e Souza (2017), baseados na definição dada pela Estratégia Internacional para Redução de Desastres (Eird/ ONU) ${ }_{19}^{19}$ o Centro de Estudos e Pesquisas sobre Desastres - Ceped da UFSC define o termo resiliência como:

a capacidade de um sistema, comunidade ou sociedade potencialmente exposta a perigos de se adaptar, resistindo ou mudando, de forma a atingir e manter um nível aceitável de funcionamento e estructura". E a definição prossegue: "Isto é determinado pelo nível da capacidade que o sistema social tem de se organizar para aumentar sua capacidade de aprender com os desastres passados para sua proteção futura e melhoria das suas medidas de redução de risco. (Brasil, 2010, apud Pacheco e Souza, 2017, p. 137)

Diante do exposto, é fundamental compreender a forma de construção e difusão de uma agenda global que encampa conceitos e/ ou paradigmas como o de resiliência pelo mundo afora, balizando ações de agentes públicos e privados. Como ilustração, tem-se o Painel
Brasileiro de Mudanças Climáticas - PBMC que, em seu relatório Mudanças Climáticas e Cidades, explica o que seriam cidades resilientes:

As populações urbanas estão enfrentando desafios crescentes impostos por numerosas pressões, tanto naturais, como o aumento dos riscos de desastres naturais, como provocados pelo homem, tais como a rápida urbanização sem um planejamento adequado e a mudança climática (100 Resilient Cities, 2014). [...] No contexto urbano, o conceito de resiliência derivou de estudos sobre a maneira pela qual os sistemas ecológicos lidam com tensões e perturbações causadas por fatores externos (Jabareen, 2013). Uma cidade resiliente tem a capacidade de resistir e de se recuperar mais facilmente frente aos impactos das mudanças climáticas (Mehrotra et al., 2009). Cidade resiliente descreve a capacidade das cidades para funcionar, onde as pessoas que vivem e trabalham nas cidades, particularmente os pobres e vulneráveis, sobrevivem e prosperaram, não importando qual o estresse ou choques com que eles se deparem (100 Resilient Cities, 2014). (PBMC, 2016, p. 21)

É interessante ver como é construída a ideia da divisão igual e da corresponsabilidade pela redução dos desastres, como se todos os sujeitos da sociedade, classes sociais, estados-nação tivessem a mesma proporção de responsabilidade pelo surgimento e crescimento das "crises". Essa ideia também se apresenta como se esses grupos/sujeitos/espaços tivessem a mesma "capacidade" de resolução das consequências catastróficas desses processos para a sociedade, ${ }^{20}$ negando, assim, as "clivagens de classe" e as "classes de risco" presentes nessa dinâmica e territórios. Sobre a resiliência urbana, Farias (2017, p. 5) escreve: 
A noção de resiliência urbana surge na sequência do aumento das catástrofes nas cidades, particularmente por causa de um modelo de urbanização difundido em escala mundial, que amplia e segmenta os danos ambientais. Importa destacar que, inicialmente restrito ao campo dos desastres naturais, o conceito de resiliência urbana se expandiu para abarcar outros fatores de riscos antrópicos, como as consequências da expansão difusa, a densificação da ocupação em áreas de risco, os problemas e transtornos decorrentes da pobreza urbana, da falta de saneamento básico, das carências dos sistemas de transportes público, etc.

Embora a citação acima apresente uma visão dicotômica dos riscos, a sua contribuição se dá na explicação da sequência cronológica de utilização do termo resiliência, ou seja, num primeiro momento ele é utilizado levando em consideração os aspectos/fenômenos naturais (que o autor chama de riscos naturais), e, em um segundo momento, o termo é estendido para as discussões que envolvem as vulnerabilidades sociais (chamadas de riscos antrópicos pelo autor).

Acerca das definições e explicações sobre resiliência, cabe destacar alguns pontos como a naturalização, não somente dos desastres, mas também da desigualdade urbana. Verifica-se tal naturalização da pobreza e vulnerabilidade socioambiental, por exemplo, em trechos do "Relatório Mudanças Climáticas e Cidades", citado anteriormente, como o que fala sobre a capacidade de "[...] pessoas que vivem e trabalham nas cidades, particularmente os pobres e vulneráveis, sobreviverem e prosperarem, não importando qual o estresse ou choques com que eles se deparem" (PBMC, 2016, p. 21).
Na verdade, entende-se esses choques/ estresses como sendo resultados das grandes contradições da produção do espaço abstrato do capital (Lefebvre, 2013). Essas contradições se agudizam no período ultraliberal vivido atualmente, por meio das ações do planejamento estratégico ligadas à urbanização neoliberal, desigual e periférica, presente nas cidades do sul global (Brenner, Peck e Theodore, 2015; Davis, 2004; Santos, 2010).

Assim, tem sido frequente a culpabilização de pessoas individualmente (ou em grupos) por problemáticas socioambientais, bem como é corriqueira a crítica à ausência de "capacidade" dessas pessoas para solucionarem sozinhas esses problemas. Em contextos neoliberais, como no Brasil, essa responsabilização tem sido crescente, fato que colabora para a emergência das discussões sobre resiliência.

Na verdade, o poder de recuperação e de seguimento das dinâmicas nos espaços afetados pelos desastres é papel do Estado que tem o dever de garantir os direitos previstos em lei, como o de moradia. Deve-se atentar para o fato que, além de falta de capacidade financeira para conduzir individualmente a propalada resiliência, a população pobre ainda vive em um contexto de negação de seus diretos básicos, como a habitação digna, que deveriam ser disponibilizados pelo Estado. Este vem se abstendo historicamente de ações que reduzam riscos e vulnerabilidades socioambientais e negando-se, inclusive, a cumprir a lei, a exemplo do Estatuto da Cidade.

Entende-se que a resposta às problemáticas socioambientais deve incluir toda a sociedade e não se limitar a responsabilizar os mais pobres e colocar a discussão somente nas mãos dos experts/tecnocratas, como tem sido 
feito, ou criar soluções de mercado. Ademais, não se deve deixar a gestão urbana e dos problemas socioambientais a cabo de empresas privadas e bancos somente. Deve-se pensar em um arcabouço de soluções que partam dos agentes sociais de maneira geral.

Ao recordar que a resiliência também se refere, teoricamente, à capacidade de pessoas, grupos ou espaços de retornarem às condições anteriores aos desastres, é importante lembrar a contribuição de Mendonça (2010) quando enfatiza que em países ou espaços pobres essa ideia não é a mais apropriada, tendo em vista que, em muitas realidades, as condições preexistentes aos desastres já eram de precariedade, "extremamente excludente, injustas e degradadas" (ibid., p. 158).

Além das instituições ligadas à redução de desastres e mudanças climáticas, há um ator financeiro multilateral, o Banco Mundial Bird, que também conceitua e define os atuais riscos e ameaças globais. Segundo as concepções do Banco Mundial, esses riscos e ameaças levam à necessidade de construção de cidades resilientes. O Bird, através de seu Relatório Anual (Banco Mundial, 2017), aponta os caminhos para a superação dos desafios e crises crescentes da sociedade global e destaca o papel da promoção da resiliência a choques e ameaças globais:

O mundo está enfrentando um conjunto de desafios cada vez maior - desde as crises crescentes de deslocamento forçado até os maiores impactos da mudança do clima - que exige um enfoque amplo para abordar as fontes de instabilidade e criar resiliência. O Banco Mundial está trabalhando cada vez mais para prever, responder e enfrentar esses desafios com conhecimentos, recursos financeiros e relacionamentos de longo prazo com clientes e parceiros. Devemos proteger os ganhos da redução da pobreza de alguns dos choques mais graves que ameaçam retroceder décadas de progresso. (Ibid., p. 25)

Cabe destacar, nessa citação do Bird, a importância dada tanto ao conhecimento sobre os riscos e ameaças quanto aos recursos financeiros para a suposta proteção dos "ganhos da redução da pobreza", pois dessas discussões é que surgem as ideias relativas à necessidade de criação/fomento de cidades inteligentes, competitivas e sustentáveis (leia-se, principalmente, fiscal e economicamente). Tais ideias e paradigmas de urbanização neoliberal sustentável são objetivadas via endividamento junto a instituições multilaterais de crédito. Sobre isso, Lazzarato (2015) aponta para a relação entre o paradigma neoliberal e a dívida pública. Para esse autor, a dívida representa uma relação de poder transversal que não reconhece as fronteiras de Estado.

Em outra frente de análise da propalada sustentabilidade e sua agenda, Sullivan (2013) analisa como o processo de crescente financeirização da vida cotidiana se estende para os discursos de conservação ambiental e sustentabilidade que, por sua vez, se combinam, em grande parte, com a financeirização do risco associado às mudanças ambientais e atmosféricas, dentro do chamado "mundo em risco" (Beck, 2009). Esses processos se dão, segundo Sullivan (2013), via estratégias pelas quais as naturezas não humanas e dinâmicas da natureza vão sendo financeirizadas por meio de monetização, precificação e mercantilização e, dessa forma, tornam-se mais um meio pelo qual o capital especulativo aposta em um valor a se realizar no futuro (Nascimento, 2020). ${ }^{21}$ 
Esse "mundo em risco", para Harvey (2014), não assusta o capital, pois [...] es perfectamente posible que el capital continúe circulando y acumulándose en medio de catástrofes medioambientales. Los desastres medioambientales generan abundantes oportunidades para que un 'capitalismo del desastre' obtenga excelentes benefícios" (p. 244). Nesse sentido, já existem, atualmente, os Catastrophe Bond - CAT (título de catástrofe), que são instrumentos de dívida de alto rendimento projetados para arrecadar dinheiro para empresas do setor de seguros, no caso de um desastre devastador. A dívida ajuda a proteger as seguradoras de custos potencialmente enormes associados a danos causados por furacões, inundações, terremotos, pandemias, etc. ${ }^{22}$

Recentemente, em 2017, o Banco Mundial emitiu os pandemic-catastrophe bonds (títulos de catástrofe pandêmica), ${ }^{23}$ estes seriam um novo teste da capacidade de segurar bens e capitais contra epidemias globais. Tal emissão marcou um esforço para expandir o uso de títulos de catástrofe - CATs e, assim, expandir a financeirização para novos setores de risco. Essa ação veio após o pior surto de Ebola já registrado. O Bird - num exemplo claro do que Klein (2008) aponta como "capitalismo de desastre" - passa a vender CATs de alto rendimento. Esses títulos pagavam às resseguradoras em resposta a pedidos de seguro para eventos como furacões. ${ }^{24}$ Grandes investidores, como fundos de pensão e doações, acumularam títulos de catástrofe nos últimos anos, na medida em que buscavam diversificação e retornos mais elevados. Com o surto do coronavírus, iniciou-se a busca por pagamentos dos chamados "títulos pandêmicos" emitidos pelo Banco Mundial. Segundo o banco, esses Coronabonds foram criados para fornecer financiamento aos países em desenvolvimento para combater a propagação de doenças infecciosas.

No que se refere à produção, em nível mundial, de dispositivos e agendas globais ligadas aos riscos e à produção de cidades, é importante recordar que, em 1994, a Estratégia Internacional para Redução de Desastres - Eird (ONU) promoveu a Conferência Mundial sobre Redução de Desastres em Yokohama no Japão. Nesse momento, houve um deslocamento das narrativas centradas em aspectos técnicos e científicos para discussões sobre a relevância dos aspectos socioeconômicos, no que tange à prevenção de desastres. Desse modo, a vulnerabilidade social e outros fatores sociais, culturais, políticos e econômicos passaram a ser também discutidos, não se enfatizando somente a temática da resiliência, priorizando-se a prevenção aos desastres. Essa prioridade foi ratificada na II Conferência, em 2005, na cidade de Hyogo, no Japão. Nessa segunda conferência, foi criado o Marco de Ação Hyogo (Eird, 2007), que foi o primeiro plano para explicar, descrever e detalhar o trabalho que é exigido de todos os setores e atores para reduzir as perdas causadas por desastres.

Após essas duas Conferências, verificou-se a busca de construção de consenso via a difusão de uma base de informações necessárias ao cumprimento de metas nacionais associadas às agendas globais, a exemplo dos Objetivos de Desenvolvimento Sustentável - ODS ${ }^{25} \mathrm{e}$ do Marco de Ação de Sendai, de 2015, ${ }^{26}$ ambos preconizados pela Organização das Nações Unidas - ONU. ${ }^{27}$ Tais processos se enquadram na perspectiva de formação de agendas e arenas globais de ação e difusão de políticas urbanas (Sabatier e Weible, 2007; Stone e Ladi, 2015), via a criação e o fortalecimento de 
redes e promoção de diálogo e cooperação entre os especialistas em desastres, agentes financeiros, planejadores urbanos entre outros. Algo que é, plenamente, preconizado em tais conferências.

Chama-se aqui a atenção para as prioridades do Marco de Ação de Sendai, de 2015, quando este as define como ações voltadas para a compreensão do risco de desastres em todas as suas dimensões, ou seja, aquelas associadas a vulnerabilidade, capacidade de resposta, exposição de pessoas e bens, características dos perigos e do meio ambiente.

No que se refere a ações semelhantes às que se vêm discutindo, no Brasil, a partir de 2011, o governo federal estabeleceu um programa multisetorial voltado para a gestão de risco e resposta a desastres chamados naturais, de forma integrada e priorizando ações de prevenção e mitigação. Segundo o IBGE (2018), 2011 foi o ano em que o País presenciou a ocorrência do maior desastre natural (sic) deste século, que culminou na morte de aproximadamente 900 pessoas e afetou mais de 300 mil na região serrana do Rio de Janeiro, além de severas perdas econômicas, da ordem de 4,8 bilhões de reais, segundo o Banco Mundial (ibid.).

Em consequência a esses fatos, o então Ministério de Ciência e Tecnologia criou, em 2011, o Centro Nacional de Monitoramento e Alertas de Desastres Naturais - Cemaden. Esse órgão tem como objetivo monitorar e emitir alertas para municípios prioritários de todo o território nacional, sobre a provável ocorrência de desastres associados a fenômenos naturais, assessorando o trabalho dos órgãos de defesa civil.

Acontece que, como não só as comunidades e as cidades estão preocupadas com essas ocorrências, as informações produzidas por instituições desse porte tornam-se, a cada dia, "mercadorias" valiosas no quadro da sociedade de risco global financeirizada que passa a ver a possibilidade da produção de um grande mercado ligado aos riscos e desastres "naturais". Segundo dados da Swiss Re, ${ }^{28}$ referentes ao aumento da população brasileira exposta ao risco de inundação, foi estimado um aumento de 33 milhões de pessoas para 43 milhões entre 2018 e 2030. 0 estudo da seguradora previu, ainda, que as perdas anuais com inundações no Brasil poderão aumentar de US\$1,4 bilhão para US\$4 bilhões em menos de 20 anos.

Seguindo nessa relação entre capital financeiro e risco de inundações, foi realizado, em 2013, em São Paulo, o seminário "Riscos de inundação no Brasil: impactos no mercado segurador, governo e sociedade". Desse evento, destacam-se dois de seus painéis que possuíam títulos bem sugestivos para o novo mercado global ligado aos desastres e riscos socioambientais.

O primeiro painel, denominado "Utilização de informações para o desenvolvimento de novos produtos", expôs as iniciativas do governo brasileiro e do mercado de seguros na previsão e mensuração das inundações. 0 painel abordava um convênio entre o Cemaden e a Confederação Nacional das Empresas de Seguros (CNseg) que permitiria, às seguradoras brasileiras, terem acesso a informações valiosas, produzidas pelo governo, para a subscrição de riscos relacionados a eventos climáticos extremos. De acordo com a diretoria da CNseg, a partir desse conjunto de dados - que inclui informações de dez fontes mantidas pela Central de Serviços e Proteção ao Seguro (Ceser) da CNseg -, sabe-se a localização geográfica de 205 mil sinistros patrimoniais do 
período de 2009 a 2013 e, ainda, como esses riscos estão espalhados no País. Tal material serve para agregar valor à subscrição de riscos, elevar seus dividendos, além de auxiliar na negociação com as resseguradoras (Swiss RE, 2013). E não para por aí a revelação dos interesses implícitos das empresas do mercado financeiro com o debate global sobre desastres e riscos.

No segundo painel, intitulado "Impacto social das inundações e o papel do gerenciamento de risco", os especialistas em gestão de riscos do Banco Mundial e da Organização das Nações Unidas (ONU) apontam que as inundações, que já haviam conquistado o posto de desastre mais frequente, agora também integram o rol dos eventos climáticos mais onerosos e difíceis de gerenciar em áreas urbanas. Segundo levantamento do Banco Mundial, esses eventos vêm aumentando significativamente nos últimos 30 anos, período em que causaram perdas de US\$3,5 trilhões. Ao analisar os agentes envolvidos - bancos e seguradoras - e seu discurso capitaneado por valores mobiliários, nota-se qual é o verdadeiro interesse da ampliação desse debate por parte deles.

Segundo outro estudo realizado no Brasil, pelo Centro de Estudos e Pesquisas sobre Desastres (Ceped) da Universidade Federal de Santa Catarina, os prejuízos causados por desastres naturais no Brasil custaram pelo menos $R \$ 182,8$ bilhões - uma média de $R \$ 800$ milhões por mês -, entre 1995 e 2014. Destacam-se, como um dos principais prejuízos contabilizados no estudo, os que ocorreram nas moradias das pessoas. Ao longo dos últimos 20 anos, em todo o País, mais de 1,8 milhão de habitações foram danificadas e mais de 185 mil foram destruídas, com Santa Catarina liderando no primeiro caso e o Rio de Janeiro, no segundo. Os prejuízos desses danos superaram $\mathrm{R} \$ 16$ bilhões (Girard, 2017).

É importante mostrar as oportunidades abertas para investimentos e empréstimos dentro do novo mercado global ligado aos desastres e riscos socioambientais, como os já apontados CATs, pois acredita-se que estas são, na realidade, o principal leitmotiv para tamanha importância dada ao tema. 0 paradigma das mudanças climáticas é a base da maioria das propostas de financiamento, empréstimos e securitização. Aqui se enfatizam algumas das recentes ações do Bird nesse intento, anunciadas em seu relatório anual de 2017 no tópico intitulado "Aproveitar as oportunidades da ação climática". Destaca-se o uso do conceito de resiliência:

O Grupo Banco Mundial comprometeu-se a aumentar seu financiamento para o clima para $28 \%$ da carteira do Grupo até 2020, em resposta à demanda dos clientes. Para cumprir esse compromisso, a organização adotou um Plano de Ação da Mudança do Clima que apresenta metas ambiciosas a serem atingidas até 2020 em áreas como energia limpa, agricultura inteligente em matéria de clima, gestão de riscos de desastres e urbanização sustentável. Desde então, o Grupo Banco Mundial tem agido rapidamente para alcançar essas metas. (Banco Mundial, 2017, p. 28)

A citação corrobora a discussão sobre os interesses ligados aos riscos, com destaque para o risco de inundação, fenômeno que pode causar grande devastação, impactos econômicos e perdas de vidas humanas. 0 estudo "Cidades e inundações: um guia para a gestão integrada do risco de inundação urbana para o século XXI" do Banco Mundial (2012) fornece, segundo o banco, orientação operacional 
para o futuro sobre como administrar o risco de inundações em um ambiente urbano em transformação e um clima em mutação. $\mathrm{O}$ documento destaca a perda de vidas e de ativos, apontando que o número de pessoas afetadas por inundações e os danos financeiros, econômicos e ativos segurados também têm aumentado. Situação na qual, apenas em 2010, 178 milhões de pessoas foram afetadas pelas inundações.

0 documento afirma que as perdas totais em anos excepcionais como 1988 e 2010 excederam $\$ 40$ bilhões. Outro fator de destaque é a maior concentração geográfica desses riscos de inundações em áreas urbanas, ligados à concentração de população e ativos nas cidades, assim como das já apontadas injustiças socioambientais (Araújo e Nascimento, 2019). Segundo o Bird, tal fato torna o dano mais intenso e mais oneroso, pois os assentamentos urbanos contêm os principais atributos econômicos e sociais e são a base de ativos de qualquer população nacional. Além disso, esses ativos econômicos concentrados nas aglomerações urbanas representam uma nova mercadoria cobiçada pelos agentes ligados ao capital financeiro, como as seguradoras e resseguradoras.

Somando-se a essa discussão sobre interesses hegemônicos relacionados aos riscos, pode-se contar com a contribuição de Beck (1998), ao relacionar os riscos à produção e distribuição das riquezas. Sobre isso, ele ressalta: Tanto los riesgos como las riquezas son objeto de repartos, y tanto éstas como aquéllos constituyen situaciones: situaciones de peligro o situaciones de classe (p. 32). Logo, a distribuição dos riscos, em grande parte dos casos, tem a ver com a sociedade de classes. Beck (ibid., p. 25) acredita ainda que En la modernidad avanzada, la producción social de riqueza va acompañada sistemáticamente por la producción social de riesgos.

Essa abordagem é bastante interessante, uma vez que dá margem para se apreender os riscos não só pelos riscos, mas em suas relações com outros contextos. Convém, portanto, pensar quem são aqueles que se encarregam de se apropriar das riquezas e quem são os que "herdam" os riscos. Nesse sentido,

La historia del reparto de los riesgos muestra que éstos siguen, al igual que las riquezas, el esquema de clases, pero al revés: las riquezas se acumulan arriba, los riesgos abajo. Por tanto, los riesgos parecen fortalecer y no suprimir la sociedad de clases. (Ibid., pp. 40-41)

Dessa forma, o denominado "mundo em risco" (Beck, 2009) aparece cada vez mais ligado aos espetaculares desastres urbanos, presentes com grande regularidade na última década, a exemplo da Pandemia Covid-19, configurando-se como oportunidades de investimentos, inclusive em capital fixo de larga escala (Harvey, 2013), que representam grandes projetos de investimento em infraestruturas resilientes por exemplo, que são absorvedores do capital financeiro ocioso ou com necessidade de (re)valorização. ${ }^{29}$

Sobre a possibilidade de grandes negócios ligados à redução de riscos e desastres e da construção de cidades sustentáveis e resilientes, chama-se a atenção para o fato de que, após um discurso de abertura proferido pelo Papa Francisco, na histórica cúpula de 2015, os chefes estaduais e governamentais dos 193 países membros da ONU elaboraram planos ambiciosos para o futuro: a Agenda 2030 e os ODS. Tal agenda global propõe metas que vão desde o fim da pobreza extrema até a 
garantia de padrões sustentáveis de produção para fomentar a cooperação global. Embora o documento de encerramento da cúpula tenha sido assinado por políticos, os governos que eles representam dificilmente conseguirão atingir as metas por conta própria, dadas as suas debilidades financeiras.

Dessa forma, os investidores e o setor privado passam a ter um papel relevante nesse sentido, assim como é possibilitada a emergência de um grande mercado para investimentos. Segundo a reportagem "Como podemos medir o progresso real nos Objetivos de Desenvolvimento Sustentável?" (Kroll, 2018), os requisitos de financiamento para os ODS ainda não cobertos são estimados entre US\$1,4 trilhão e US\$2,5 trilhões. A necessidade de financiamento apenas para o Objetivo 6 do ODS's ("Garantir disponibilidade e gestão sustentável de água e saneamento para todos"), por exemplo, foi estimado pelo Banco Mundial em 28,4 mil milhões de euros por ano. ${ }^{30}$

A respeito dos desastres e dos riscos, destaca-se que uma visão mais holística sobre eles é iniciada nos anos 1970, período que coincide com o início da derrocada do Estado nacional keynesiano de bem-estar social (Brenner, Peck e Theoddore, 2015) e o avanço das políticas neoliberais e ideias pós-modernas. Dentro do discurso neoliberal, associado a um pretenso desenvolvimento sustentável, tem-se o lançamento, via organismos multilaterais e suas conferências, de objetivos para as cidades como: manter e, se possível, meIhorar a qualidade de vida das pessoas e promover a resiliência e a responsabilidade local para a recuperação de desastres. Tudo isso aliado a um apelo à construção de consensos e de menor participação do Estado-nação em políticas socioeconômicas.
Retomando a discussão sobre o relatório anual do Bird (Banco Mundial, 2017), em outro tópico do documento, sobre suas ações prioritárias, o banco aponta para a "Criação de resiliência a desastres e crises". Destaca sua atuação, nesse sentido, com formação de expertise para o assunto e sua carteira de investimentos e ganhos de oportunidade, com iniciativas e projetos ligados à promoção da chamada resiliência. 0 relatório enfatiza que:

Os desastres naturais custam anualmente US\$520 bilhões em perdas e impelem cerca de 26 milhões de pessoas para a pobreza. A gestão de riscos de desastres é uma das pedras fundamentais da agenda de resiliência do Banco Mundial, com uma carteira que aumentou quase cinquenta por cento durante os exercícios financeiros de 2012-2016, de US\$3,7 bilhões para US\$5,4 bilhões. Atualmente o Banco Mundial trabalha em mais de 70 países ajudando a integrar a gestão de riscos de desastres aos esforços de desenvolvimento por meio de uma combinação de financiamento, assistência técnica, capacitação e atividades de intercâmbio de conhecimentos. Ele apoia os países clientes com ferramentas inovadoras para identificar o risco e os produtos financeiros, a fim de proteger os orçamentos nacionais. (Banco Mundial, 2017, p. 28)

Ao reforçar os desastres como algo especificamente natural, desconsiderando as causas mais enraizadas desses problemas, com ênfase para as desigualdades (que não são somente resultados, mas causas dos desastres), o Banco Mundial é claro ao tratar como "clientes" os países cujos desastres possam vir a ocorrer e/ou aqueles com os quais já mantém "parceria", confirmando o que se vem discutindo neste artigo. Ou quando explana 
que visa produzir uma "combinação de financiamento, assistência técnica, capacitação e atividades de intercâmbio de conhecimentos". Destaca-se, assim, a conformação de agendas e de um mercado.

Ou seja, constata-se que os riscos e os desastres passam de problemas e tragédias socioambientais a negócios lucrativos, na concepção desses organismos multilaterais, como o próprio banco que se coloca como panaceia para possíveis problemáticas vindouras, visando lucros e qualquer forma de ganho financeiro. Um dos trechos da citação acima corrobora essa afirmativa, quando expõe que: "A gestão de riscos de desastres é uma das pedras fundamentais da agenda de resiliência do Banco Mundial" (ibid.).

Acrescenta-se que boa parte dessas narrativas é encabeçada pelas linhas programáticas e agendas de atuação de vários outros organismos multilaterais, como ONU, OCDE, BID, etc. Através de seus empréstimos, assistência técnica e "recomendações" de best practices, tais organismos tendem a modelar um determinado padrão de uso do recurso público e de organização do Estado, assim como de reestruturação econômica e territorial. Essas instituições difundem agendas, ações via programas e políticas públicas que seguem critérios empresariais de rentabilidade e um modelo de gestão estatal terceirizada, algo que pode ser visto hoje com a análise da ascensão de dispositivos neoliberais como as Parcerias Público-Privadas - PPPs.

Os organismos multilaterais mencionados atuam como agentes de transferência de conhecimento e normas transnacionais, criando um campo ou arena de ações (Sabatier e Weible, 2007). Essa arena, por sua vez, visa à redução de risco para seus investimentos/financiamentos - via endividamento de cidades e países como aparato ou dispositivo de captura de seus governos (Lazzarato, 2015), ${ }^{31}$ que almejam se tornar competitivos e receptivos de novos investimentos e são induzidos a pensar que só tornando seus territórios sustentáveis, resilientes e inteligentes, como apregoado por esses agentes e arenas, vão conseguir tal feito; além de assegurar a abertura de mercado e a redução de riscos para os investimentos de seus parceiros estratégicos nas cidades.

Acrescenta-se que, para a realização dos grandes negócios ligados ao chamado desenvolvimento sustentável e à produção de infraestruturas (resilientes) - capital fixo de larga escala - ligadas à denominada resiliência e aos desastres, são necessários também grandes investimentos, com o uso do fundo público. Esses investimentos possuem a articulação de duas lógicas dentro da produção do espaço (Harvey, 2011; 2013). Uma lógica territorial, encampada, na maioria das vezes, pelo Estado, via aumento de endividamento, relacionada à produção de grandes projetos dentro ou não de um programa de governo ou projeto político; e uma lógica financeira, a do capital irrestrito e eclético (Nascimento, 2015), podendo-se citar, como exemplo, as ações do Banco Mundial e das resseguradoras e seus Catastrophe Bond - CAT e Coronabonds, conforme apontado anteriormente.

A lógica dos organismos financeiros está ligada ao desenvolvimento do capital fictício e/ ou capital portador de juros que, por seu turno, está implicado na evolução do crédito para investimentos em larga escala, presente no investimento ou na formação bruta de capital fixo, a exemplo das chamadas "infraestruturas resilientes" 32 para promoção do desenvolvimento sustentável. Tal lógica está relacionada, 
também, aos gastos governamentais e a parcelas de bens e serviços que estão sendo adquiridos pelos entes privados.

Brandão, Fernández e Ribeiro (2018) apontam a replicação, a difusão, o utopismo e a reprodutibilidade crescente de uma gama de políticas, programas e projetos de desenvolvimento local e regional e sustentável. Essas políticas são apologizadas e profetizadas pelos "manuais de boas práticas", apregoados pelos organismos internacionais. Servem, ainda, de impulso para a construção de "planos estratégicos" ligados à governança urbana neoliberal e que são resultados da proliferação de uma grande quantidade de agências consultoras ligadas a uma expertise global produtora de consensos relativos à produção e à gestão das cidades pelo mundo.

A política neoliberal redefiniu o papel do Estado Nacional, no quadro da globalização e da crise fiscal, fazendo com que ele diminuísse seu papel em diversas áreas. Contudo, o Estado desobriga-se de várias políticas públicas e procura também estimular a autonomia dos estados e municípios via reestruturações regulatórias, características de um processo de reescalonamento das ações do próprio Estado (Brenner, 2018). Esse estímulo tem o intuito de que tais entes subnacionais formulem, implementem e gestem seus programas e projetos de desenvolvimento via concessões de toda sorte (viárias, de saneamento, etc.) e ligações diretas com grandes investidores em potencial, característica presente na urbanização de cunho neoliberal e financeirizada. Destaca-se que a própria ONU, desde sua Conferência Habitat II, preconiza tal descentralização (Onu-Habitat, 2009).

Essas políticas, muitas vezes, geram custos de oportunidades, pois o Estado deixa de investir em áreas prioritárias, como a produção e/ou melhoria de moradias e infraestruturas urbanas, levando milhares de pessoas a ocuparem áreas de risco em assentamentos precários. Além disso, o Estado, muitas vezes, também, repassa a produção e gestão de serviços urbanos básicos para as mãos da iniciativa privada, fato característico de processo de urbanização neoliberal e que gera, por um lado, uma exclusão de acesso a tais serviços para a população mais pobre e precarizada e, por outro lado, o crescimento dos lucros e ganhos financeiros por parte dos agentes capitalistas. ${ }^{33}$

\section{Considerações finais}

O capitalismo em seu atual período de crise estrutural passa a produzir crises constantes. Assim, países periféricos convivem, há algumas décadas, com uma espécie de ajuste fiscal permanente que, por sua vez, faz parte de um processo de acumulação primitiva permanente. Toda essa dinâmica tem moldado o padrão latino-americano de integração econômica e desenvolvimento capitalista em um contexto de convergência de múltiplas crises, o que leva à produção de um espaço com alto padrão de desigualdade e mais suscetível aos riscos e vulnerabilidades socioambientais.

Nesse sentido, a produção de uma teoria crítica urbana aparece como uma importante contribuição para abordagens do tipo relacional, que ajudem a desvendar a interdependência entre fatores econômicos, políticos, sociais e processos ecológicos que, juntos, conformam as paisagens urbanas altamente desiguais e profundamente injustas das cidades capitalistas. 
Neste estudo, além dos debates teóricos sobre os conceitos de risco e de resiliência, para melhor compreendê-los (bem como a suas temáticas correlatas), recorreu-se a uma análise sobre a transferência, difusão e mobilidade de narrativas hegemônicas da chamada sociedade de risco global e da urbanização neoliberal. Tais discursos e agendas são utilizados para a produção de consensos ligados a algumas das ideias-mestre da Nova Agenda Urbana Habitat III e dos ODS, com destaque para os ODS 11 e 13, que são pressupostos para a implementação de uma agenda neoliberal "sustentável" para a produção do espaço urbano nas cidades e metrópoles pelo mundo afora.

Narrativas como aquelas apresentadas ao longo do texto, a exemplo do termo "resiliência" e de seus desdobramentos, podem ser mais bem compreendidas dentro do quadro de crise estrutural do sistema capitalista, porque esse contexto leva à (re)produção de determinado consenso em torno de tais narrativas. A partir delas, de maneira geral, a responsabilização sobre a situação de vulnerabilidade social e de problemáticas ambientais que acometem populações inteiras é colocada sobre indivíduos de forma isolada e acrítica. Ocorre, assim, a produção de um discurso perverso que desobriga o Estado de resolver problemas históricos, como o da provisão de habitação para uma massa crescente de pessoas alijadas da sociedade salarial e da seguridade social, devido ao avanço do ultraliberalismo. Ao mesmo tempo, essa dinâmica - atrelada às mencionadas narrativas - cria e mantém um mercado "promissor", ligado às tragédias socioambientais, a exemplos dos citados Catastrophe Bond - CAT e Coronabonds.
Ideias e conceitos como o de resiliência surgem em momentos de crise social muito grande e tentam culpabilizar e condenar os indivíduos pelo fracasso social, profissional, entre outros. Ou ainda "acusam" as pessoas, mesmo que de forma velada, por não terem se "preparado de forma correta" para eventos naturais extremos e cada vez mais constantes. Cria-se, dessa forma, a ideia da privatização e individualização do fracasso ligado à elaboração de consensos que levam os indivíduos a aceitarem as injustiças socioespaciais e/ou socioambientais (Araújo e Nascimento, 2019; Souza, 2019; Soja, 2014) como resultado de sua única e exclusiva culpa.

Assim, verifica-se a ausência da produção de um raciocínio crítico espacial sobre a condição de risco e vulnerabilidade socioambiental de grande parte da população moradora das chamadas áreas de risco, por exemplo. Raciocínio e reflexão necessários para a construção de uma compreensão do processo de produção social e desigual do espaço, através dos quais se possa entender que o espaço é socialmente produzido e pode, portanto, ser socialmente alterado. Alia-se a isso o fato de que as problemáticas socioespaciais ligadas ao risco não possuem causas naturais - embora estejam relacionadas, muitas vezes, a fenômenos naturais -, mas se constituem como resultado de uma construção sócio-histórica (Araújo, 2019; Araújo e Nascimento, 2019).

Acredita-se que, a partir da análise exploratória efetivada neste estudo, passa se refletir de forma mais crítica sobre a relação entre os desastres e as grandes transformações na relação sociedade-natureza e suas implicações. Além disso, através desta pesquisa, pôde-se verificar a emergência/aprofundamento 
de uma espécie de "capitalismo de desastre" (Klein, 2008) que vê os riscos como oportunidades de negócios - e seus altos lucros e dividendos -, contexto no qual os desastres e as tragédias podem virar oportunidades de superlucros. Uma outra possível via de análise de tal lógica são as representações e as vivências dos riscos, desastres e tragédias dentro de um cotidiano de medo, vulnerabilidade e injustiça para as populações pobres das cidades do capitalismo periférico.

0 entendimento acerca dos processos que envolvem os riscos e as vulnerabilidades socioambientais nas cidades só é possível através de uma abordagem que entenda a natureza como universal, ou seja, como interdependente e inseparável da sociedade. Essa problematização deve ocorrer via a compreensão da interação entre as dinâmicas socioespaciais ligadas à reestruturação econômica/territorial (associada ao processo de acumulação do capital que comanda o atual fenômeno de urbanização planetária, neoliberal e desigual). 0 processo de acumulação do capital tem se realizado de forma cada vez mais intensa, gerando/ampliando toda sorte de injustiças sociais e ecológicas/ambientais e/ou socioespaciais.

Defende-se a ideia de que é necessário compreender as problemáticas socioambientais, a exemplo dos riscos e vulnerabilidades, não como dinâmicas meramente naturais, mas como dinâmicas fortemente enraizadas aos problemas ligados à busca do desenvolvimento - agora dito sustentável - bem como relacionadas a processos mais amplos: históricos, políticos, sociais, econômicos, entre outros. Observou-se que existe uma construção sociopolítica e institucional multiescalar da noção de crise climática e sua correlata legitimação via o paradigma das mudanças climáticas de causa antrópica, e não da relação sociometabólica e contraditória entre homem e natureza no capitalismo.

Destaca-se que a Nova Agenda Urbana e os ODS tratam o mercado financeiro como um parceiro fundamental do "Desenvolvimento Urbano Sustentável", como foi possível observar nos documentos do Banco Mundial e da ONU sobre o financiamento para os ODS. Verificou-se, ainda, que a própria ONU, assim como outros organismos multilaterais, vem sendo uma grande difusora de narrativas que mercantilizam a produção do espaço urbano, com o uso de conceitos como cidades sustentáveis e inteligentes, além de toda sorte de investimentos/endividamentos de agentes do mercado/governos para alcançar tais paradigmas. Esses discursos levam a crer que a mercantilização/privatização/financeirização da moradia e dos serviços e infraestruturas urbanas - e da própria natureza - irão garantir, por si só, qualidade de vida e ampliação de acesso a bens e serviços para todos.

Por fim, defende-se que, aos indivíduos e às comunidades, sejam dadas oportunidades para a realização de direitos ligados à sua reprodução social e uma vida digna. E não somente a culpabilização pelas problemáticas socioambientais ou a conta a ser paga por dívidas e gastos provenientes de ações do Estado, em favor de agentes do mercado e da construção de grandes negócios da/na produção do espaço urbano. Produção esta que se realiza, cada vez mais, a partir de narrativas e consensos advindos de escalas e agentes alheios e/ou indiferentes à realidade na qual vivem milhões de pessoas que conformam a chamada "sociedade de risco". 


\section{[I] https://orcid.org/0000-0002-9436-9970}

Universidade Federal da Paraíba, Centro de Ciências Exatas e da Natureza, Programa de Pós-Graduação em Geografia. João Pessoa, PB/Brasil.

alexandre.sabino@academico.ufpb.br

\section{[II] https://orcid.org/0000-0002-7038-8077}

Secretaria da Educação e da Ciência e Tecnologia do Estado da Paraíba. João Pessoa, PB/Brasil. calinemendes@gmail.com

\section{Notas}

(1) Mike Davis descreve a urbanização desigual que se desenvolve no chamado terceiro mundo da seguinte maneira: La dinámica de urbanización del Tercer Mundo compendia y confunde al mismo tiempo los precedentes de la Europa y la Norteamérica del siglo XIX y principios del XX. En China, hallamos la mayor revolución industrial de la historia en la palanca arquimedeana que está trasladando a una población del tamaño de la europea de aldeas rurales a ciudades ahogadas em humo neblinoso que se elevan hacia las nubes. [...] La urbanización en el resto de regiones en vías de desarrollo se ha desconectado radicalmente, por lo tanto, de la industrialización, e incluso del desarrollo per se. Hay quien sostendría que esto no es sino uma expresión de una tendencia inexorable: la propensión inherente del capitalismo de silicio a desligar el crecimiento de la producción del aumento del empleo. Pero en África subsahariana, América Latina, Oriente Próximo y partes de Asia, la urbanización-sin-crecimiento constituye obviamente más el legado de una coyuntura política global -la crisis de la deuda de finales de la década de los setenta y las subsiguientes reestructuraciones de las economías del Tercer Mundo dirigidas por el FMI en la de los ochenta- que el producto de una ley de hierro del avance tecnológico" (Davis, 2004, pp. 8-9).

(2) Com destaque para o ODS 11 - Cidades e Comunidades Sustentáveis, que tem como objetivo tornar as cidades e os assentamentos humanos inclusivos, seguros, resilientes e sustentáveis.

(3) Cita-se, por exemplo, o caso de Josué de Castro que já cunhava a expressão socioambiental quando da escrita do livro Homens e Caranguejos (1966), sendo o primeiro brasileiro a usar o termo (Porto-Gonçalves, 2012). Há também alguns pesquisadores de programas de pós-graduação, como os Prodemas (Programas de Pós-Graduação em Desenvolvimento e Meio Ambiente), que têm uma abordagem interdisciplinar com relação aos temas que envolvem o meio ambiente, entre outros.

(4) Disponível em: https://www.un.org/sustainabledevelopment/es/objetivos-de-desarrollosostenible/. Acesso em: 20 set 2019.

(5) O Acordo de Paris foi firmado na COP-21. Este representa um consenso entre os países-membros da ONU em torno da mitigação dos efeitos da mudança do clima.

6) As abordagens nem sempre se apresentam com essas denominações, porém leva-se em conta, aqui, a natureza das contribuições, para além de nomenclaturas. 
(7) A abordagem sobre espaço relacional é predominante nas concepções de Geografia pautadas no estruturalismo, na fenomenologia, nos marxismos e no pensamento pós-moderno.

(8) Segundo Macedo (2017), em sua tese sobre a participação das cidades brasileiras na governança multinível das mudanças climáticas, "As investigações no Brasil sobre cidades e mudanças climáticas, no âmbito da academia e de órgãos federais por meio de seus institutos e programas, tendem a se concentrar nos temas relacionados a questões sociais, como riscos, vulnerabilidade e adaptação [ou resiliência] (p. 31; grifos nossos).

(9) Para Veyret (2007, p. 20): “A manutenção de escalas temporais e espaciais coloca nesse momento o geógrafo no coração dessa problemática".

(10) Sobre isso, cabe ressaltar que no Brasil, historicamente, conformou-se uma força de trabalho barata, segregada e excluída da cidade legal. Segundo Maricato (2013), vivemos a industrialização dos baixos salários, que condicionou uma urbanização de baixos salários. Tal fato faz parte da formação socioespacial geradora de vulnerabilidades nas cidades brasileiras.

(11) Exemplo disso, e de como a vulnerabilidade pode ser uma das causas mais fortes dos desastres, pode ser visto na análise feita por Klein (2008) sobre como interesses de agentes capitalistas, ligados à despossessão de moradores pobres da cidade de Nova Orleans, foram viabilizados por meio da tragédia provocada pelo furacão Katrina. Klein aborda de forma contundente a emergência do que chama "capitalismo de desastre" em seu livro A doutrina do choque (ibid.).

(12) Segundo Beck (2017, p. 99): La clase de riesgo arroja luz sobre la intercección de las situaciones de riesgos y las situaciones de classe.

(13) Segundo Mészáros (2011), existe uma incompatibilidade do capitalismo com o atendimento das necessidades reais das pessoas e sua autorreprodução. Para o autor, quanto mais aumentam a competitividade e a concorrência intercapitalista, mais nefastas são suas consequências, destacando: a destruição e/ou precarização, sem paralelos em toda a era moderna, da força humana que trabalha e a degradação crescente do meio ambiente, na relação metabólica entre homem, tecnologia e natureza, conduzida pela lógica societal subordinada aos parâmetros do capital e do sistema produtor de mercadorias.

(14) Aqui se faz uma ressalva com relação ao termo, pois alguns estudiosos tratam a perspectiva mista a partir da junção entre a abordagem natural e antrópica (Castro, 1999). Neste estudo, ao invés da visão antrópica, opta-se por tratar da perspectiva social e sua relação com a natureza e seus fenômenos ou, como coloca Mendonça (2010), opta-se por tratar os "fenômenos imbricados de contingências naturais e sociais".

(15) Em 1992, é criada a Red de Estudios Sociales en Prevención de Desastres en América Latina (La RED), afirmando o paradigma habitualmente designado de "construção social" do risco, em oposição ao clássico paradigma naturalista.

(16) A esse respeito, Beck (1998, p. 39) coloca que: Sin embargo, los riesgos no se agotan en consecuencias y daños que ya han tenido lugar, sino que contienen esencialmente un componente futuro. [...] Así pues, los riesgos tienen que ver esencialmente con la previsión, con destrucciones que aún no han tenido lugar, pero que son inminentes, y que precisamente en este significado ya son reales hoy. 
(17) Tais incertezas também fazem parte da dinâmica do que alguns analistas apontam como sendo a atual etapa do capitalismo, chamada de "regime de acumulação com dominância da valorização financeira". Nesse paradigma, ocorre um peso maior na valorização financeira sobre a produtiva. Daí tem-se uma "nova" lógica que se impõe ao processo total de acumulação e reprodução capitalistas; tal lógica tem, dentre suas características, ser avessa ao risco, mas sobrevive e se reproduz na instabilidade, porque enseja e reproduz a especulação (Chenais, 2005; Nascimento e Fernandes, 2014).

(18) Urge fugir de tais simplificações. Mas ainda há muito o que se fazer nesse sentido, tendo em vista que, por exemplo, para Souza (2015, p. 26), “O mais comum, nos estudos geomorfológicos, climatológicos, pedológicos etc., quando se faz referência à presença e às interferências da sociedade, é referir-se a isso como 'fator antrópico'. Com isso, toda uma complexidade se esvai e se oculta, em favor de um termo-valise que tudo contém e nada ou quase nada explica".

(19) A Eird é um secretariado interagências das Nações Unidas, cujo mandato é de coordenar, promover e fortalecer a redução do risco de desastres em nível mundial, regional, nacional e local, buscando, com isso, reduzir os impactos dos desastres. Possui a missão de facilitar e apoiar ações para proteger as vidas e aumentar a resiliência das comunidades. A Eird está sediada em Genebra, na Suíça, com escritórios regionais nas Américas, África, Ásia e Europa.

(20) Nesse sentido, verificam-se ações como a da Secretaria Nacional de Proteção e Defesa Civil (Sedec) que lançou, no ano de 2011, uma campanha denominada: "Construindo Cidades Resilientes: Minha Cidade está se Preparando". Tal campanha afirma que a cidade resiliente é "aquela que tem capacidade de resistir, absorver e se recuperar de forma eficiente dos efeitos de um desastre e, de maneira organizada, prevenir que vidas e bens sejam perdidos" (Unisdr, 2012).

(21) "Recentemente, tem se realizado uma profusão de criação e difusão de green bonds ou "títulos verdes" ligados a fluxos financeiros públicos e privados para investimentos e atividades que reduzem as emissões de carbono ou aumentam a resiliência aos impactos das mudanças climáticas (Alide, 2019), uma das instituições promotoras desse mercado é o Grupo de Estudio de Finanzas Verdes del G20 (GFSG)" (Nascimento, 2020, p. 239).

(22) Segundo reportagem intitulada Banco Mundial, OMS e governos usam com sucesso títulos de catástrofe, os "títulos de catástrofes estão se tornando a arma para todos os fins contra as consequências de pandemias, terremotos e grandes tempestades nos círculos do Banco Mundial, da OMS e dos governos. O conceito de transferência de risco, que já provou seu valor em regiões industrializadas, está atraindo crescente interesse em regiões subdesenvolvidas. [...] [Um] Outro exemplo é o MultiCat Bond do México e subsequentemente o "Fonden 2017 CAT Bond". Eles foram emitidos pelo Banco Internacional de Reconstrução e Desenvolvimento (Bird), com um volume de emissão de US \$290 milhões para garantir os riscos de catástrofes naturais no México. Os prêmios foram financiados pelo estado do México. Esse bônus CAT foi emitido em agosto de 2017. Um evento de terremoto ocorreu um mês depois, e o capital foi pago em um curto espaço de tempo (Haefliger, 2019; tradução nossa).

(23) Sobre os pandemic-catastrophe bonds ou os Coronabonds, há várias reportagens, de jornais ligados ao mercado financeiro, que noticiaram tais títulos ligados à pandemia Covid-19 (Sars): "Coronavirus Outbreak Tests World Bank's Pandemic Insurance" (The Wall Street Journal, 2020); “O meu nome é Bond, Coronabond. O que significa a palavra da discórdia europeia?” (TSF Portugal, 2020); "Coronavirus: les "catastrophe bonds" sont-ils vraiment le remède financier dont nous avons besoin?" (La Tribune, 2020). 
(24) "Investors Cash In on Ebola Bonds That Haven't Paid Out" (Lauerman e Vossos, 2019).

(25) Em 2015, os países adotaram a Agenda 2030 para o Desenvolvimento Sustentável e seus 17 Objetivos de Desenvolvimento Sustentável. Relacionados à temática analisada, destacam-se os Objetivos do Desenvolvimento Sustentável: ODS 11: Tornar as cidades e os assentamentos humanos inclusivos, seguros, resilientes e sustentáveis; e ODS 13: Tomar medidas urgentes para combater a mudança do clima e seus impactos.

(26) O Marco de Ação de Sendai 2015-2030, adotado como novo paradigma por países para a redução de riscos de desastres, reforça a ideia de "aprimorar o trabalho científico e técnico sobre a redução do risco de desastres e sua mobilização através da coordenação de redes existentes e de institutos de pesquisa científica em todos os níveis e regiões". Disponível em: http:// www.defesacivil.pr.gov.br/sites/defesa-civil/arquivos_restritos/files/documento/2018-12/ MarcodeSendaiPortugues.pdf. Acesso em: 15 set 2019.

(27) Outra iniciativa da ONU foi a criação do Centro de Excelência de Redução do Risco de Desastres (CERRD) cuja missão é sensibilizar os países, especialmente do Bric, sobre a importância de incluir a redução do risco de desastres como um componente central do desenvolvimento sustentável.

(28) A empresa suíça Swiss Re Group é uma das líderes mundiais do setor de resseguros, fornecedora atacadista de resseguro, seguro e outras formas de transferência de risco baseadas em seguros. Disponível em:< http://www.swissre.com/latin_america/brasil_assimilou_importancia_seguro_ contra_riscos_inundacoes.html>. Acesso em: 29 set 2019.

(29) Dentre os exemplos, pode-se destacar a destruição de Nova Orleans pelo furacão Katrina em 2005, os tsunamis que engoliram partes do Japão em 2010 e, paralelamente, ameaçaram o mundo com uma tragédia nuclear, advinda da danificação da usina nuclear de Fukushima.

(30) O relatório "Financing investment in selected SDGs" (UN, 2018) mostra a discussão sobre os novos papéis do Estado e do capital financeiro para a construção de infraestruturas resilientes, promoção de uma industrialização do tipo inclusiva e sustentável e construção de cidades inclusivas, seguras, resilientes, sustentáveis e inteligentes, quando aborda as necessidades e as possibilidades de financiamento, para a realização dos 17 Objetivos de Desenvolvimento Sustentável - ODS, e os caminhos dos empréstimos e endividamentos para entidades políticas subnacionais..

(31) Destaca-se que o sistema de crédito representa a formação de dívidas tanto públicas como privadas (Lazzarato, 2013; 2015); estas são o atual motor do sistema capitalista, principalmente, em sua fase de dominância das finanças (Chesnais, 1996).

(32) Infraestruturas ligadas à redução de risco, com enfoque estrutural, como, por exemplo, obras de drenagens para evitar inundações, ações de adaptação às mudanças climáticas (Fundação Konrad Adenauer, 2015).

(33) No documento "Como construir cidades mais resilientes - um guia para gestores públicos locais" (Unisdr, 2012) é apontado e defendido o investimento em resiliência como oportunidade de negócios. Mostrando que "todos" se beneficiam com o investimento em Redução de Riscos de Desastres e Resiliência. Em um de seus trechos, o documento aponta que "O risco de não prestar atenção à redução de riscos de desastres pode levar a sérios problemas econômicos e deterioração dos ecossistemas, assim como à perda da confiança da população e de investidores" (ibid., p. 19). 


\section{Referências}

ACSERALD, H.; CAMPELLO, C. A.; BEZERRA, G. N. (2009). O que é justiça ambiental. Rio de Janeiro, Garamond.

AgAMBEN, G. (2005). O que é um dispositivo? Outra Travessia. Santa Catarina, n. 5, pp. 9-16.

ALIDE - Asociación Latinoamericana de Instituciones Financieras para el Desarrollo (2019). Mercado de Bonos Verdes: ¿quiénes son sus protagonistas? G20/ALIDE.

ALMEIDA, L. Q. (2011). Por uma ciência dos riscos e vulnerabilidades na geografia. Mercator. Fortaleza, v. 10, n. 23 , pp. 83-99.

ARAÚJO, C. M. de (2019). "Áreas de risco" e problemáticas socioambientais: uma reflexão sobre a produção e apropriação do espaço urbano em Campina Grande (PB). Tese de doutorado. Recife, Universidade Federal de Pernambuco.

ARAÚJO, C. M. de; NASCIMENTO, A. S. (2019). Produção de desigualdades e injustiças socioambientais urbanas: apontamentos sobre Campina Grande - PB. In: XIII ENANPUR. Anais... Natal.

BANCO MUNDIAL (2012). Banco Internacional de Reconstrução e Desenvolvimento (BIRD)/ Associação Internacional de Desenvolvimento (AID). Cidades e Inundações: um Guia para a Gestão Integrada do Risco de Inundação Urbana para o Século XXI. Washington DC.

(2017). BancolnternacionaldeReconstruçãoeDesenvolvimento(BIRD)/AssociaçãoInternacional de Desenvolvimento (AID) - Relatório Anual 2017. Disponível em: https://openknowledge. worldbank.org/bitstream/handle/10986/27986/211119PT. pdf?sequence=9\&isAllowed=y. Acesso em: 25 set 2019.

BECK, U. (1998). La sociedad del riesgo: hacia una nueva modernidad. Paidós, Barcelona. (2009). World at risk. Cambridge, Polity Press.

(2017). Las metamorfoses del mundo. Barcelona, Paidós-Espasa Libros.

BRANDÃO, C. A.; FERNÁNDEZ, V. R.; RIBEIRO, L. C. de Q. (orgs.) (2018). Escalas espaciais, reescalonamentos e estatalidades: lições e desafios para América Latina. Rio de Janeiro, Letra Capital/ Observatório das Metrópoles.

BRENNER, N. (2014). Teses sobre a urbanização. e-metropoles, n. 19, ano 5.

(2018). Espaços da urbanização: o urbano a partir da teoria crítica. Rio de Janeiro, Letra Capital/ Observatório das Metrópoles.

(2020). "Máquinas de crescimento urbano - mas em que escala?". RIBEIRO, L. C. Q. (org.). As metrópoles e o capitalismo financeirizado. Rio de Janeiro, Letra Capital/Observatório das Metrópoles, pp. 245-274.

BRENNER, N.; PECK, J.; THEODORE, N. (2015). “Urbanismo neoliberal. La ciudad y el império de los mercados". In: OBSERVATÓRIO METROPOLITANO DE MADRID (ed.). El mercado contra la ciudad: sobre globalización, gentrificación y políticas urbanas. Madrid, Traficantes de Sueños.

BÜDENBENDER, M.; AALBERS, M. B. (2019). How subordinate financialization shapes urban development: the rise and fall of Warsaw's Suewiec business district. International Journal of Urban and Regional Research, v. 43, n. 4, pp. 666-684. 
CANTOS, J. O. (2008). Cambios en la consideración territorial, conceptual y de método de los riesgos naturales. Revista Scripta Nova. Barcelona, v. XII, n. 270.

CASTRO, A. L. C. (1999). Manual de Planejamento em Defesa Civil. Brasília, Ministério da Integração Nacional, Secretaria de Defesa Civil.

CHESNAIS, F. (1996). A Mundialização do Capital. São Paulo, Xamã.

(2005). “O Capital portador de juros: acumulação, internacionalização, efeitos econômicos e políticos”. In: CHESNAIS, F. (org.). A finança mundializada. São Paulo, Boitempo, pp. 35-67.

DAVIS, M. (2004). Planeta de Ciudades-Miseria: involución urbana y proletariado informal. Artículos, n. 26.

EIRD - Estratégia Internacional para a Redução de Desastres (2007). Marco de Ação de Hyogo 20052015. Aumento da resiliência das nações e das comunidades frente aos desastres. Genebra, EIRD/ UNISDR. Disponível em: http://www.defesacivil.pr.gov.br/sites/defesa-civil/arquivos_restritos/ files/documento/2018-12/MarcodeHyogoPortugues20052015.pdf. Acesso em: 15 set 2019.

FARIAS, J. A. (2017). Resiliência: um bom conceito para o projeto e a reforma urbana? In: XVII ENANPUR. Anais... São Paulo.

FILGUEIRA, H. J. A. (2013). “Os desastres relacionados com fenômenos naturais no contexto dos sistemas organizacionais". In: GARCIA, J. P. M (org.). Desastres na Paraíba: riscos, vulnerabilidade e resiliência. 1. João Pessoa, Editora Universitária da UFPB.

FUNDAÇÃO KONRAD ADENAUER (2015). Cidades resilientes. Rio de Janeiro, Fundação Konrad Adenauer.

FURTADO, F. P. (2015). Em nome do clima: instituições e práticas na ambientalização das finanças no Brasil. Tese de doutorado. Rio de Janeiro, Universidade Federal do Rio de Janeiro.

GIRARD, G. (2017). Desastres naturais custaram ao Brasil R\$ 182 bi em 20 anos. Disponível em: <https://sustentabilidade.estadao.com.br/blogs/ambiente-se/desastres-naturais-custaram-aobrasil-r-182-bi-em-20-anos/>. Acesso em: 21 ago 2018.

HAEFLIGER, M. (2019). Catastrophe bonds in the tension between ESG integration and SDG contribution payments. Disponível em: https://yoursri.com/esg-and-carbon/newsletter/topic-of-the-monthcatastrophe-bonds-in-the-tension-between-esg-integration-and-sdg-contribution-payments. Acesso em: 22 jul 2019.

HARVEY, D. (2011). O enigma do capital: e as crises do capitalismo. São Paulo, Boitempo.

(2013). Os limites do Capital. São Paulo, Boitempo.

(2014). Diecisiete contradicciones del capital y el fin del neoliberalismo. Madrid, Traficantes de Sueños.

(2016). Urbanismo y desigualdade social. Madri, Siglo XXI.

IBGE - Instituto Brasileiro de Geografia e Estatística (2018). População em áreas de risco no Brasil. Rio de Janeiro, IBGE.

JAJAMOVICH, G. (2013). Miradas sobre intercambios internacionales y circulación internacional de ideas y modelos urbanos. Andamios, v. 10, n. 22, pp. 91-111.

KLEIN, N. (2008). A doutrina do choque: a ascensão do capitalismo de desastre. Rio de Janeiro, Nova Fronteira. 
KROLL, C. (2018). How to measure progress sustainable development goals. Disponível em:< https:// www.weforum.org/agenda/2018/07/how-to-measure-progress-sustainable-developmentgoals/>. Acesso em: 22 jul 2019.

LA TRIBUNE (2020). Coronavirus: les "catastrophe bonds" sont-ils vraiment le remède financier dont nous avons besoin?". Disponível em: https://www.latribune.fr/opinions/tribunes/coronavirusles-catastrophe-bonds-sont-ils-vraiment-le-remede-financier-dont-nous-avons-besoin-843539. html. Acesso em: 3 maio 2021.

LAUERMAN, J.; VOSSOS, T. (2019). Investors cash in on ebola bonds that haven't paid out. Disponível em: https://www.bloomberg.com/news/articles/2019-08-14/ebola-bond-pays-investorsmillions-while-congo-battles-outbreak. Acesso em: 3 maio 2021.

LAZZARATO, M. (2013). La fábrica del hombre endeudado. Ensayo sobre la condición neoliberal. Buenos aires, Amorrortu.

(2015). Gobernar a través de la deuda: tecnologias de poder del capitalismo neoliberal. Buenos Aires/Madrid, Amorrortu.

LEFEBVRE, H. (2013). La produción del espacio. Madri, Capitán Swing.

MACEDO, L. S. V. de (2017). Participação de cidades brasileiras na governança multinível das mudanças climáticas. Tese de doutorado. São Paulo, Universidade de São Paulo.

MARICATO, E. (2013). "É a questão urbana, estúpido". In: MARICATO, E. et al. Cidades rebeldes: Passe livre e as manifestações que tomaram as ruas do Brasil. São Paulo, Boitempo/Carta Maior.

MENDONÇA, F. (2009). Geografia, geografia física e meio ambiente: uma reflexão a partir da problemática socioambiental urbana. Revista da Anpege, v. 5, pp. 123-134.

(2010). Riscos e vulnerabilidades socioambientais urbanos: a contingência climática. Mercator. v. 9, pp. 153-163.

MÉSZÁROS, I. (2011). Para além do capital: rumo a uma teoria da transição. São Paulo, Boitempo.

MORAES, A. C. R. (2005). Meio Ambiente e Ciências Humanas. São Paulo, Annablume.

NASCIMENTO, A. S.; FERNANDES, A. C. (2014). O jogo, o tijolo e o balão: uma análise da relação entre capital financeiro e megaeventos e sua consequente produção do espaço da/na metrópole In: II CONFERÊNCIA INTERNACIONAL MEGAEVENTOS E A CIDADE. Anais... Rio de Janeiro. Disponível em: https://www.academia.edu/42164686/O_JOGO_O_TIJOLO_E_O_BAL\%C3\%830_ UMA_AN\%C3\%81LISE_DA_RELA\%C3\%87\%C3\%830_ENTRE_CAPITAL_FINANCEIRO_E_ MEGAEVENTOS_E_SUA_CONSEQUENTE_PRODU\%C3\%87\%C3\%830_DO_ESPA\%C3\%870_DA_ NA_METR\%C3\%93POLE. Acesso em: 10 set 2019.

NASCIMENTO, A. S. (2015). Do fixo ao fluxo: expressões da acumulação rentista-patrimonial ampliada na produção do espaço da metrópole do Recife. Tese de doutorado. Recife, Universidade Federal de Pernambuco.

(2020). A fome do capital e a expropriação dos bens comuns - land/green grabbing e suas relações com a reprodução do discurso neoliberal por trás do fenômeno das mudanças climáticas. Caminhos de Geografia. Edição especial: I CIGEO-DR. Uberlândia, dez., pp. 222-248. 
ONU-HABITAT (2009). Directrices Internacionales sobre Descentralización y Acceso a los Servicios Básicos para Todos. Nairobi, ONU- Hábitat.

. (2016). Nova Agenda Urbana-Declaração de Quito sobre cidades sustentáveis e assentamentos humanos para todos. Quito, ONU-Habitat.

ONU - Organização das Nações Unidas (2020). Objetivos do Desenvolvimento Sustentável. Disponível em: https://nacoesunidas.org/pos2015/. Acesso em: 23 mar 2020.

PACHECO, R. F.; SOUZA, S. R. E. de (2017). A psicologia junto às políticas públicas em situações de emergências e desastres. Pretextos - Revista de Graduação em Psicologia da PUC Minas. Belo Horizonte, v. 2, n. 3. Disponível em:<http://periodicos.pucminas.br/index.php/pretextos/article/ view/14252/11202>. Acesso em: 20 set 2018 .

PAULANI, L. (2008). Brasil Delivery: servidão financeira e estado de emergência econômico. São Paulo, Boitempo.

PBMC - Painel Brasileiro de Mudanças Climáticas (2016). “Mudanças Climáticas e Cidades”. In: RIBEIRO, S. K.; SANTOS, A. S. (eds.)]. Relatório Especial do Painel Brasileiro de Mudanças Climáticas. Rio de Janeiro, PBMC, Coppe - UFRJ.

PECK, J.; THEODORE, N. (2010). Mobilizing policy: Models, methods, and mutations. Geoforum, n. 41, pp. 169-174.

PORTO-GONÇALVES, C. W. (2012). A Globalização da natureza e a natureza da globalização. Rio de Janeiro, Civilização Brasileira.

ROMERO, H.; FUENTES, C.; SMITH, P. (2010). Ecología política de los riesgos naturales y de la contaminación ambiental en Santiago de Chile: necesidad de justicia ambiental. Revista Scripta Nova, v. XIV, n. 331(52). Barcelona.

SABATIER, P. A.; WEIBLE, C. M. (2007). "The advocacy coalition framework: innovations and clarifications". In: SABATIER, P. A. (ed.). Theories of the policy process. Cambridge/MA, Westview.

SANCHÉZ, R. (2012). El riesgo y el peligro como factores de construcción y organización de la ciudad de Santiago de Chile. Revista Scripta Nova, v. XVI, n. 418(45). Barcelona.

SANTOS, B. de S. (2010). Refundación del Estado en América Latina: Perspectivas desde una epistemología del Sur. Lima, Instituto Internacional de Derecho y Sociedad.

SMITH, N. (1988). Desenvolvimento Desigual: Natureza, capital e a produção de espaço. Rio de Janeiro, Bertrand Brasil.

SOJA, E. W. (2014). Em busca de la justicia espacial. Valência, Tirant Humanidades.

SOUZA, M. L. (2015). Proteção ambiental para quem? A instrumentalização da ecologia contra o direito à moradia. Mercator. Fortaleza, v. 14, n. 4, Número Especial, pp. 25-44.

(2019). Ambientes \& Territórios: uma introdução à ecologia política. Rio de Janeiro, Bertrand Brasil.

STONE, D.; LADI, S. (2015). Global public policy and transnational administration. Public Administration, v. 93, n. 4 , pp. $839-855$.

SUERTEGARAY, D. M. (2017). Religar a geografia: natureza e sociedade. Porto Alegre, Compasso.

SULLIVAN, S. (2013). Banking Nature? The Spectacular Financialisation of Environmental Conservation. Antipode, v. 45, n. 1, pp. 198-217. 
SWISS RE (2013). “O Brasil já assimilou a importância do seguro contra os riscos de inundações?” Disponível em: <http://www.swissre.com/latin_america/brasil_assimilou_importancia_seguro_ contra_riscos_inundacoes.html>. Acesso em: 29 set 2018.

THE WALL STREET JOURNAL (2020). Coronavirus Outbreak Tests World Bank's Pandemic Insurance. Disponível em: https://www.wsj.com/articles/coronavirus-outbreak-tests-world-bankspandemic-insurance-11582136298. Acesso em: 3 maio 2021.

THOMAS, A. L. (1993). "Ciencias sociales y desastres naturales en América Latina: un encuentro inconcluso". In: MASCREY, A. Los desastres no son naturales. Lima, La Rede.

TOMINAGA, L. K. et al. (orgs.) (2012). Desastres naturais: conhecer para prevenir. São Paulo, Instituto Geológico.

TSF PORTUGAL (2020). O meu nome é Bond, Coronabond. O que significa a palavra da discórdia europeia? Disponível em: https://www.tsf.pt/portugal/economia/o-meu-nome-e-bondcoronabond-o-que-significa-a-palavra-da-discordia-europeia-12012329.html. Acesso em: 3 maio 2021.

UN - United Nations (2018). Financing investment in selected SDGs. Disponível em: https:// developmentfinance.un.org/2018-financing-investment-selected-sdgs. Acesso em: 23 jul 2019.

UNISDR (2012). Como construir cidades mais resilientes um guia para gestores públicos locais. Disponível em: https://www.gov.br/mdr/pt-br/assuntos/protecao-e-defesa-civil/informacoesuteis/copy2_of_Guiacomoconstruircidadesresilientes.pdf. Acesso em: 10 maio 2021.

VEYRET, Y. (2007). Os riscos: o homem como agressor e vítima do meio ambiente. São Paulo, Contexto.

WILCHES-CHAUX (1993). "La vulnerabilidad global”. In: MASCREY, A. Los desastres no son naturales. Lima, La Rede.

Texto recebido em 31/out/2020

Texto aprovado em 14/jul/2021 